\title{
Osteoid osteoma of the acetabular roof: a case report
}

\author{
Youssef Benyass* (D), Bouchaib Chafry, Kaldadak Koufagued and Belkacem Chagar
}

\begin{abstract}
Background: An acetabular location of osteoid osteoma is rare and represents less than $1 \%$ of cases. The purpose of this clinical case report is to highlight the unusual location of osteoid osteoma and the technical difficulty of its removal.

Case presentation: We report a case of a 17-year-old Moroccan Arab boy who presented with pain in his right hip with lameness. The diagnosis of osteoid osteoma was made by imagery and confirmed by histological examination. The treatment consisted of a complete percutaneous resection scanno-guided of the nidus. The evolution was marked by complete healing with total and definitive disappearance of symptoms after 1 year.

Conclusions: Osteoid osteoma of the acetabular roof is rare. The diagnosis is now easy because of the evolution of imaging. Treatment is exclusively surgical. Complete resection guarantees the absence of recurrence. The difficulty of the surgical procedure is due to the deep localization of the osteoid osteoma and because it is endosseous, it is also dangerous due to anatomical relationships and the small size of the osteoid osteoma.
\end{abstract}

Keywords: Osteoid osteoma, Percutaneous treatment, Interventional radiology

\section{Background}

Osteoid osteoma is a common benign bone tumor. It represents 10 to $12 \%$ of all benign bone tumors [1]. In most cases it occurs in the first three decades of life with a male predominance. It occurs primarily in the lower limbs. Acetabular involvement is very rare $(\leq 1 \%)$ [2]. Imaging is the key to diagnosis. Treatment of osteoid osteoma is exclusively surgical. Complete resection guarantees an absence of recurrence. If the localization of the osteoid osteoma is deep, then the surgical procedure is difficult. The purpose of this clinical case report is to highlight this unusual site of osteoid osteoma and the technical difficulty of its removal.

\section{Case presentation}

A 17-year-old Moroccan Arab boy without significant medical history presented last year with pain in his right hip that was predominantly nocturnal and sensitive to aspirin. A clinical examination showed lameness while walking without limitation of hip movements. The

* Correspondence: youssef.benyass@gmail.com

Department of Orthopedic Trauma, Mohamed V Military Hospital, University Mohamed V-Souissi, Rabat, Morocco results of laboratory tests were normal. Plain radiographs of his right hip did not show any visible lesion. A computed tomography (CT) scan showed a $10 \mathrm{~mm}$ osteoid osteoma located in the roof of the right acetabulum (Fig. 1).

He was operated in the radiology department with surgical aseptic conditions, under spinal anesthesia and in the lateral decubitus position. The lesion was identified by contiguous $2 \mathrm{~mm}$ thickness CT scan (Fig. 2). Then the nidus was extracted with percutaneous curettage using a trephine. A CT scan immediately after resection confirmed complete resection (Fig. 3). Histological examination confirmed the diagnosis.

After a period of 1 year, evolution was marked by a complete recovery with total and definitive disappearance of symptoms.

\section{Discussion}

Osteoid osteoma is a benign bone tumor of small size, described for the first time by Jaffe in 1935. It represents 10 to $12 \%$ of benign bone tumors; it usually affects individuals during the first three decades of life, with a predominance in males [3]. It is characterized by the 


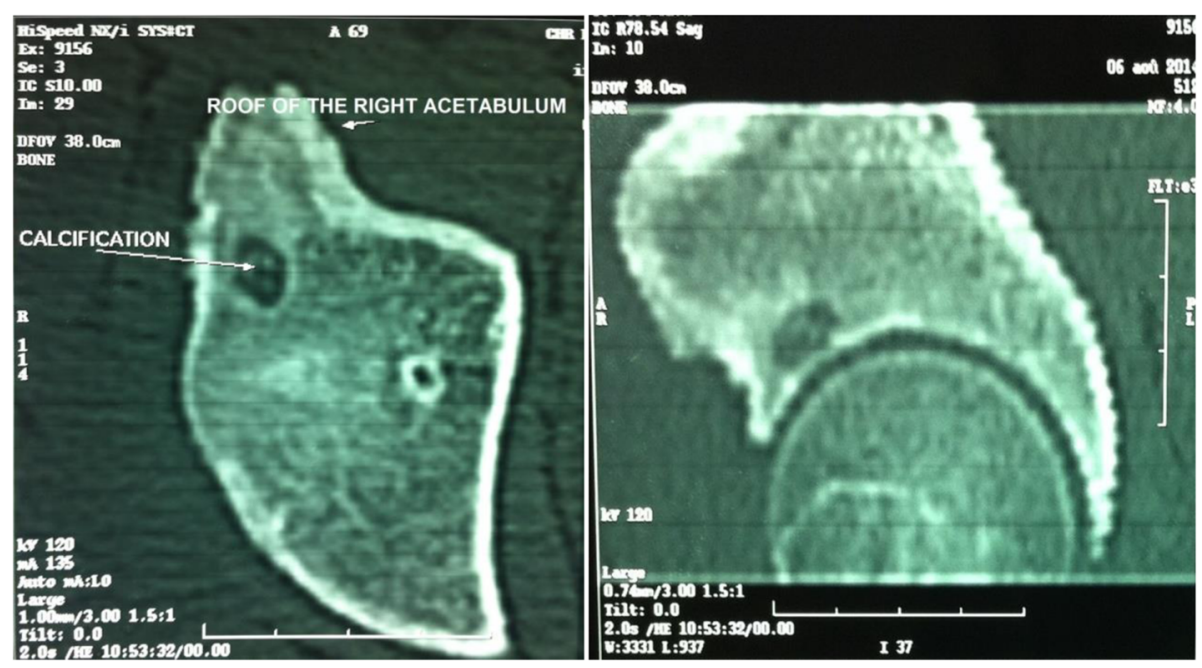

Fig. 1 Computed tomography scan showing an osteoid osteoma at the acetabular roof

presence of a central hypervascular nidus which may calcify. It is formed by an amalgamation of mineralized osteoid spans whose size does not exceed $15 \mathrm{~mm}$. An osteosclerosis reaction of varying size surrounds the nidus.

Osteoid osteoma preferentially localizes at the shaft of long bones near the metaphyseal junctions, with a predilection for the lower limbs [4]. It is located very rarely on flat bones. Clinical manifestations are usually typical, such as night pain with insomnia, relieved by aspirin taking. In our case, the symptoms were typical and associated with lameness. This pain is related to high levels of prostaglandins in the nidus, which induce an inflammatory response [5]. A clinical examination is usually normal.

Conventional radiographs can objectify intracortical lacuna, containing sometimes a punctuated matrix surrounded by a sclerotic reaction more or less important. In joint juxta articular forms, the peripheral condensation is low and there is often a synovial thickening revealing intra-articular effusions, which can mislead the diagnosis [6]. In the case of our patient, plain radiographs did not objectify the injury. Bone scintigraphy is indicated in front of an evocative board confirming a suggestive image on plain radiographs or detecting lesions in normal radiographs. It shows an early spot, very hyperfixant that is characteristic of the nidus surrounded by a less intense hyperfixing area. It is very sensitive but not specific [7].

CT has significantly increased the speed of diagnosis as the early clinical signs appear. It also allows you to locate precisely the lesion and the exact size of the nidus. It is the gold standard provided thin sections of 1 to $2 \mathrm{~mm}$ thickness are used [8]. CT in our patient
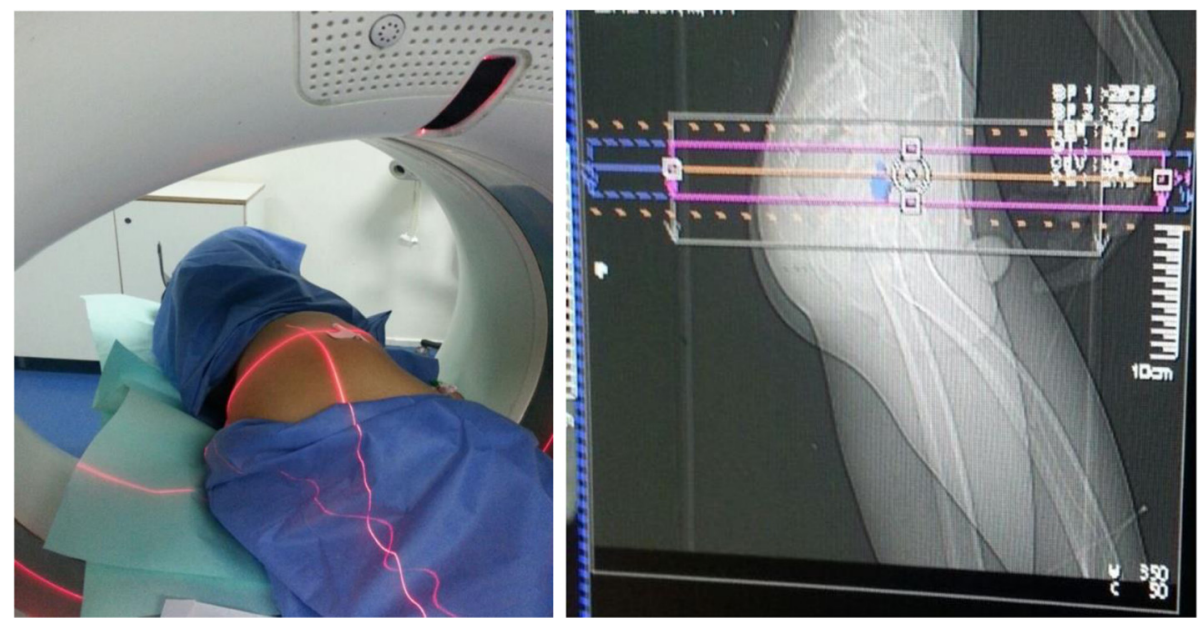

Fig. 2 Locating osteoid osteoma by contiguous computed tomography slices 


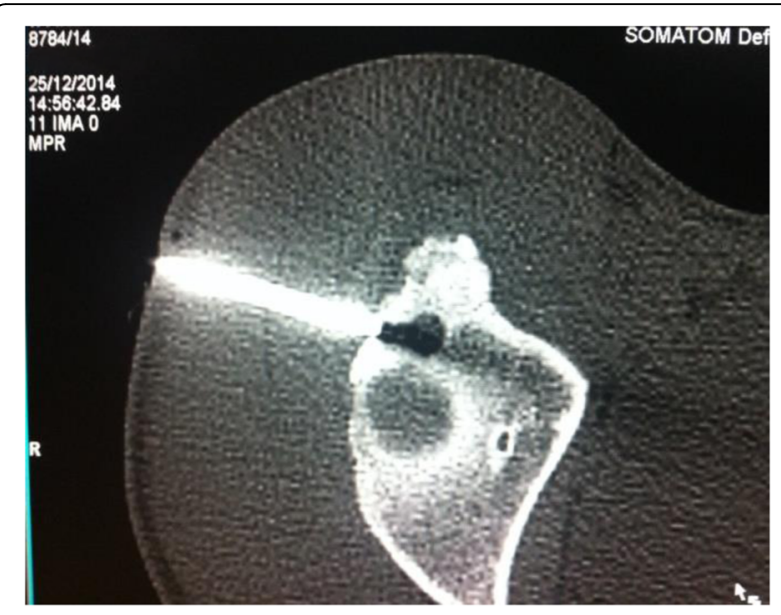

Fig. 3 Computed tomography control immediately after resection confirmed the complete resection of osteoid osteoma

confirmed the diagnosis of osteoid osteoma. It showed the presence of a spongy $10 \mathrm{~mm}$ lacuna at the roof of his right acetabulum, surrounded by an osteosclerosis reaction, with the presence of central punctuated calcifications.

The use of magnetic resonance imaging (MRI) is justified especially in cases of doubt in the diagnosis as in unusual localizations, such as juxta-articular or intramedullar. It shows not only the nidus but also the inflammatory reaction modifications in bone marrow and surrounding soft tissue. The use of dynamic sequences after gadolinium injection improves the sensitivity of MRI (92\%) so much that it becomes equal to that of CT [9].

Treatment of osteoid osteoma is surgical. Bloc resection has been the standard therapy. However, difficulty in locating the nidus, despite using preoperative or perioperative imaging, results in a wide bone resection compared to the small size of the lesion. Open surgical treatment is effective when the nidus is resected completely, but remains a relatively invasive technique which weakens the bones, especially long bones, which can justify resorting to a bone graft or internal fixation osteosynthesis and postoperative immobilization [10]. The percutaneous treatment of osteoid osteoma has gradually replaced surgery due to advances in CT and development of percutaneous surgery tools. They are applicable in the vast majority of locations of osteoid osteoma. They allow intraoperative control of needle placement with high accuracy, lower complication rates, faster recovery, and probably a reduction in recurrences [11].

Percutaneous resection under CT guidance is an effective technique and noninvasive. It is practiced in the scanner room under strict aseptic conditions and under local or general anesthesia. It is useful especially in deep locations such as the acetabulum because it avoids dislocating the hip for a direct approach. This procedure uses a coaxial system comprising a guidewire, a trocar mandrel and a toothed outer sheath to protect the soft tissue, a cannulated drill bit to penetrate the bone to the edge of the nidus in the case of a deep lesion, and a trephine of 3 to $8 \mathrm{~mm}$ in diameter for the excision of the nidus. Some use a motor to move the wick and the trephine.

A CT control checks the total resection of the nidus. In a case of incomplete excision, a new borehole can be done. Histological evidence of the presence of a nidus within the resected bone core is reported in 50 to $100 \%$ of cases depending on the series [12].

Other less invasive alternatives have been developed, mostly under CT guidance, comprising alcoholization, thermocoagulation by radiofrequency, laser photocoagulation, and cryotherapy. Currently, surgery is reserved for percutaneously inaccessible locations (posterior wall of the spinal lesion or root canal) or locations adjacent to neurovascular structures $(<1 \mathrm{~cm})$ [11].

From the first postoperative hours, the virtual disappearance of pain or complete attenuation supports the use of a total resection. Pain disappears after 24 hours in most cases, but can sometimes persist for a month [13]. The diagnostic approach to a possible recurrence or persistence of an osteoid osteoma is particularly delicate because the surgical act transforms the tumor site. Except in the absence of osteosynthesis material, CT is still the key examination in seeking a "forgotten" nidus in the affected zone [14].

\section{Conclusions}

Osteoid osteoma is a small benign bone tumor. It is rarely located on the acetabulum. CT is the gold standard for diagnosis. The use of MRI is justified if there is doubt in the diagnosis especially in unusual localizations, such as juxta articular or intramedullar forms. Treatment of osteoid osteoma is exclusively surgical. Percutaneous resection under $\mathrm{CT}$ guidance is an effective technique, especially in the forms with deep anatomical location, where it is extremely efficient. It allows perioperative control with high precision, lower complication rates, faster recovery and probably a reduction in recurrences. Several procedures and techniques for treating osteoid osteoma percutaneously are currently available to the clinician. Surgical treatment is reserved for percutaneously inaccessible locations or locations near neurovascular structures.

\section{Abbreviations}

$C T$, computed tomography; MRI, magnetic resonance imaging

\section{Acknowledgements}

This manuscript was prepared during the corresponding author's training and was supported by the authors. 


\section{Authors' contributions}

$\mathrm{YB}, \mathrm{KK}, \mathrm{BoC}$, and $\mathrm{BeC}$ were the consultants responsible for diagnosing and treating the patient and his clinical follow-up. They all reviewed the patient case and data, completed subsequent drafts of the manuscript, and were major contributors in writing the manuscript. All authors read and approved the final manuscript.

\section{Competing interests}

The authors declare that they have no competing interests.

\section{Consent for publication}

Written informed consent was obtained from the patient's legal guardian(s) for publication of this case report and any accompanying images. A copy of the written consent is available for review by the Editor-in-Chief of this journal.

Received: 1 April 2016 Accepted: 28 July 2016

\section{Published online: 24 August 2016}

\section{References}

1. Greenspan A. Benign bone-forming lesions: osteoma, osteoid osteoma, and osteoblastoma. Skeletal Radiol. 1993;22(7):485-500.

2. Ruggieri P, Gasbarrini A, Ferraro A, Campanacci L. Osteoid osteoma: direct visual identification and intralesional excision of the nidus with minimal removal of bone. Bone Joint J. 1999:81(5):814.

3. Lucas DR. Dahlin's Bone Tumors: General Aspects and Data on 11,087 Cases. Am J Clin Pathol. 1996:106(5):693.

4. Assoun J, Railhac JJ, Bonnevialle P, et al. Osteoid osteoma: percutaneous resection with CT quidance. Radiology. 1993;188(2):541-7.

5. Greco F, Tamburrelli F, Ciabattoni G. Prostaglandins in osteoid osteoma. Int Orthop. 1991;15(1):35-7.

6. Kransdorf MJ, Stull MA, Gilkey FW, Moser RP. Osteoid osteoma. RadioGraphics. 1991;11:671-96.

7. Helms CA, Hattner RS, Vogler JB. Osteoid osteoma: radionuclide diagnosis. Radiology. 1984;151(3):779-84.

8. Davies M, Cassar-Pullicino VN, Davies MA, McCall IW, Tyrrell PN. The diagnostic accuracy of MR imaging in osteoid osteoma. Skeletal Radiol. 2002:31(10):559-69.

9. Liu PT, Chivers FS, Roberts CC, Schultz CJ, Beauchamp CP. Imaging of Osteoid Osteoma with Dynamic Gadolinium-enhanced MR Imaging 1. Radiology. 2003;227(3):691-700.

10. Cantwell CP, Obyrne J, Eustace S. Current trends in treatment of osteoid osteoma with an emphasis on radiofrequency ablation. Eur Radiol. 2004 14(4):607-17.

11. Roqueplan F, Porcher R, Bousson V, Zouari L, Younan T, Hamzé B, Larédo JD. Résultats a long terme du traitement par résection percutanée et photocoagulation au laser interstitiel des ostéomes osteoides. J Radiol. 2005; 86(10):1372-3

12. Parlier-Cuau C, Nizard R, Champsaur P, Hamze B, et al. Osteoid Osteoma of the Acetabulum Three Cases Treated by Percutaneous Resection. Clin Orthop Relat Res. 1999:365:167-74.

13. Sans N, Galy-Fourcade D, Assoun J, Jarlaud T, et al. Osteoid Osteoma: CT-guided Percutaneous Resection and Follow-up in 38 Patients. Radiology. 1991;212(3):687-92

14. Bonnevialle P, Railhac JJ. Osteoma osteoide y osteoblastoma. EMC-Aparato Locomotor. 2001:34(2):1-7.

\section{Submit your next manuscript to BioMed Central and we will help you at every step:}

- We accept pre-submission inquiries

- Our selector tool helps you to find the most relevant journal

- We provide round the clock customer support

- Convenient online submission

- Thorough peer review

- Inclusion in PubMed and all major indexing services

- Maximum visibility for your research

Submit your manuscript at www.biomedcentral.com/submit 